\title{
QUEM PODE COMER NA MESA DO CAPITÃO? INTERTEXTUALIDADE E ALTERIDADE NAS OBRAS DE KATHERINE ANNE PORTER E ANA MARGARIDA DE CARVALHO
}

\author{
Dora Nunes Gago ${ }^{1^{*}}$ \\ ${ }^{1}$ Universidade de Macau, Taipa, Macau, China
}

\begin{abstract}
Resumo
Este artigo pretende analisar as relações intertextuais e a alteridade nos romances The Ship of Fools (1962) da escritora americana Katherine Anne Porter e Não se Pode Morar nos Olhos de um Gato (2016) da autora portuguesa Ana Margarida de Carvalho. Partindo de uma abordagem comparatista, com o intuito de analisar semelhanças no seio das diferenças, recorrendo aos contributos teóricos de Tiphaine Samoyault, Ingedore Koch, Paul Voestermans, entre outros, discutiremos o modo como a intertextualidade se assume como porta de entrada na alteridade - elemento fulcral nos dois romances. Com efeito, em ambas as obras, num ambiente de confinamento claustrofóbico, os olhares hostis de desconfiança lançados ao "outro" revelam preconceitos conducentes à injustiça e à discriminação social. Em ambos os casos, "a mesa do capitão" simboliza um estatuto privilegiado, acessível apenas a uma elite minoritária. Por fim, abordaremos a forma como a alteridade confere sentido às inter-relações estabelecidas nas duas obras, sublinhando uma visão pessimista da natureza humana, de inegável atualidade, que nos faz refletir no modo como em pleno século XXI, numa sociedade globalizada, percebemos e (con)vivemos com o "outro".

Palavras-chave: Alteridade, Intertextualidade, Katherine Anne Porter, Ana Margarida de Carvalho, Navio, Preconceito
\end{abstract}

\footnotetext{
"Atualmente é professora associada de Literatura no Departamento de Português da Universidade de Macau e diretora do mesmo departamento. Doutora em Literaturas Românicas Comparadas pela Universidade Nova de Lisboa, mestra em Estudos Literários Comparados e graduada em Ensino de Português e Francês. Foi leitora do Instituto Camões na Universidade da República Oriental do Uruguai; investigadora de pós-doutoramento na Universidade de Aveiro e na Universidade de Massachusetts Amherst. Seu e-mail é: doragago@um.edu.mo ORCID: 0000-0002-6300-1575.
} 


\title{
WHO CAN EAT AT THE CAPTAIN'S TABLE? \\ INTERTEXTUALITY AND ALTERITY IN THE WORKS OF \\ KATHERINE ANNE PORTER AND ANA MARGARIDA DE \\ CARVALHO
}

\begin{abstract}
This article aims to analyse the intertextual relations and the alterity in the novels The Ship of Fools (1962) by the American writer Katherine Anne Porter and Não se Pode Morar nos Olhos de um Gato [You Can't Live in the Eyes of a Cat] (2016) by the Portuguese author Ana Margarida de Carvalho. Starting from a comparatist approach in order to analyse similarities within the differences and using the theoretical contributions of Tiphaine Samoyault, Ingedore Koch and Paul Voestermans among others, we will discuss how intertextuality becomes an entrance into alterity - a core element in the two novels. In fact, in both works, in an atmosphere of claustrophobic confinement, the hostile looks of distrust cast at the "other" reveal the prejudices that lead to injustice and social discrimination. In both cases, "the captain's table" symbolises a privileged status, accessible only to an elite minority. Finally, we will look at how alterity confers meaning on the inter-relationships established in the two works, underlining a pessimistic view of human nature, of undeniable actuality, that makes us reflect on how in a globalised society in the 21st century we perceive and live (together) with the "other".

Keywords: Alterity, Intertextuality, Katherine Anne Porter, Ana Margarida de Carvalho, Ship, Prejudice
\end{abstract}


Introdução

A forte impressão provocada pelo romance The Ship of Fools da escritora americana Katherine Anne Porter é referida por Ana Margarida de Carvalho, numa entrevista concedida a Pietro Gabriel Pacheco (2019). Dessa obra, cuja ação decorre em 1931, num barco que faz a travessia entre o México e a Alemanha, Ana Margarida de Carvalho gravou em sua memória, entre outros elementos, duas perguntas fulcrais: Quem pode comer na mesa do capitão?" e "Quem são aqueles que vão no porão do navio?” (2019, p. 4). Podemos considerar que essas questões seminais terão inspirado, mais tarde, a construção do seu romance intitulado Não se pode morar nos olhos de um gato (2016).

Partindo de uma abordagem comparatista, com o intuito de analisar semelhanças, no seio das diferenças, equacionaremos de que forma a alteridade se delineia como alicerce nos dois romances. Mobilizando os contributos teóricos de Tiphaine Samoyault, Michel Foucault, Ingedore Koch, Paul Voestermans e Linda Hutcheon, partindo da intertextualidade, analisaremos o modo como a alteridade, configurada numa atmosfera claustrofóbica de confinamento, principia a desenhar-se através da desconfiança mútua perante o "outro", progredindo, posteriormente, através da relação estabelecida entre diversas personagens e do direito ou da proibição de acesso à "mesa do capitão". Por fim, discutiremos a forma como a alteridade configura uma metáfora da condição humana de inegável atualidade em pleno século XXI.

Primeiramente, importa referir que The Ship of Fools (1962), o único romance de Porter, foi escrito ao longo de mais de vinte anos, entre agosto de 1941 e agosto de 1961 (UNRUE, 2005, p. 249). A obra divide-se em três partes (o embarque, no alto mar e os portos), centrando-se na viagem realizada por um grupo muito heterogêneo, no navio "Vera", que parte de Vera Cruz, no México, com destino a Bramerhaven, na Alemanha, em 1931. Essa travessia tem a duração de vinte e seis dias, num tempo em que o fascismo e as ditaduras totalitárias germinavam pela Europa.

Antes de o leitor embarcar nessa viagem, Porter fornece as coordenadas essenciais a um melhor entendimento de comportamentos e inter-relações entre as personagens, apresentando seus nomes e nacionalidades, como em uma peça de teatro. Nessa esteira, deparamo-nos com trinta personagens relevantes que ocupam a primeira classe do barco e que importa, antes de tudo, apresentarmos. Assim, o grupo mais numeroso é constituído pelos alemães (num total de dezessete), englobando: Thiele, o comandante do navio; o Dr. Schumann (médico); Herr Karl Glocken (um corcunda que vendeu a sua loja no México e está de regresso à Alemanha); Frau Rittersdorf ; o casal Hutten e o seu buldogue branco; Herr Karl Baugartner, um advogado alcoólatra que viaja com o filho e a mulher; Herr Graf, um fanático religioso em estado terminal, acompanhado pelo sobrinho; Herr Lowenthal, judeu e industrial; Freytag, alemão, casado com uma judia, ligado a uma companhia de petróleos no México. Além disso, no que toca às personagens oriundas de outras nacionalidades, devemos destacar: seis estudantes de medicina 
cubanos; seis mexicanos; um sueco conflituoso chamado Arne Hansen; os Lutz, uma família de três elementos de origem suíça; cantores e bailarinos espanhóis de uma trupe de zarzuela que se consideram ciganos (Amparo, Lola, Concha, Pastora, Pepe, Tito, Manola, Pancho e os gêmeos de seis anos, Ric e Rac, filhos de Lola). Por último, importa ainda salientar a presença dos americanos William Denny (engenheiro químico do Texas), Mary Treadwell (uma senhora de meia idade, divorciada), os jovens pintores David Scott e Jenny Brown. Além disso, são referidos, de forma muito geral, no romance, os passageiros de terceira classe, num total de oitocentas e setenta e seis pessoas - espanhóis, homens, mulheres, crianças, trabalhadores das plantações de açúcar de Cuba, sendo deportados de regresso à Espanha, após o colapso das explorações açucareiras.

Por seu turno, Não se pode morar nos olhos de um gato, de Ana Margarida de Carvalho centra-se no naufrágio de um navio negreiro clandestino, ao longo da costa do Brasil, no final do século XIX. A esse acidente sobrevivem: o capataz, um escravo, um criado (José, que saberemos depois tratar-se de uma mulher fugida da prostituição e cujo nome é Clara), um padre (Marcolino), um jovem solitário (Nunzio), a esposa do dono do navio (Teresa), sua filha (Emina) e um menino com cerca de um ou dois anos (Henrique), filho de uma escrava falecida no desastre. Além disso, "sobrevive" igualmente uma santa de madeira, a "Nossa Senhora de Todas as Angústias", que assume a narração do primeiro capítulo e irá assistindo ao desenrolar da ação. Essas personagens, após o naufrágio, refugiam-se em uma praia deserta que irá desaparecer quatro vezes por dia, ao sabor das marés.

Tanto em The Ship of Fools quanto em Não se Pode Morar nos Olhos de um Gato notamos que transparece a atmosfera claustrofóbica em que se desenrola a existência das personagens, ancoradas a um espaço de transição, próximo do “não lugar”, cunhado por Marc Augé (1992). Esta categoria de "não lugar” aplicase tanto aos navios que integram os romances, como à praia deserta. Na verdade, em ambos os romances, as personagens distanciadas cada vez mais da realidade, da civilização, são conduzidas para os abismos do desespero e da alienação aos mais diversos níveis. Esses abismos serão explicitados através da relação com o "outro", num exercício de alteridade iniciado, a um nível mais incipiente, através da intertextualidade.

\section{A intertextualidade: uma porta para a alteridade}

A presença da intertextualidade é relevante e abundante nos dois romances, contudo, no presente trabalho focaremos, sucintamente, apenas em alguns exemplos, com o intuito de percebermos de que modo as relações intertextuais funcionam como uma porta aberta para a alteridade.

Como já referimos, Ana Margarida de Carvalho mencionou a importância da leitura de The Ship of Fools como elemento relevante para a construção do seu romance. Além disso a intertextualidade, marcada pela presença de outros textos (ou intertextos), é notória, tanto nos títulos das duas obras quanto no início das mesmas. 
Antes de tudo, importa relembrar que a relação intertextual tem sido uma preocupação permanente dos teóricos da literatura desde a Antiguidade Clássica, tal como é salientado por Richard Bauman, que localiza esse interesse desde que Aristóteles, na Poética, refletiu acerca de tragédias baseadas na Ilíada e na Odisseia (BAUMAN, 2004, p. 13). A intertextualidade refere-se ao carácter produtivo de um texto, à sua relação com a miríade de "reinos discursivos" (CARDEN, 2018, p. 24) de onde ele emerge, que o percorrem e são, através dele, trilhados. Desse modo, tendo sido um termo cunhado por Júlia Kristeva em 1966, inspirado pela obra de Bakhtin, a intertextualidade apresenta inicialmente o texto como um espaço no qual os processos relacionais constituem o foco de análise em detrimento das estruturas estáticas (FRIEDMAN, 1991). Assim, o texto convocará um diálogo entre diversas obras, intersetando também discursos culturais, ideologias e a própria linguagem. Nessa medida, de acordo com Kristeva (1980, p. 66, minha tradução1), "qualquer texto é a absorção e a transformação de outro. A noção de intertextualidade substitui a de intersubjetividade, e uma linguagem poética é lida como pelo menos dupla”. Essa linha de pensamento é retomada por Laurent Jenny, ao afirmar que "fora da intertextualidade, a obra literária seria muito simplesmente incompreensível, tal como as palavras duma língua ainda desconhecida" (JENNY, 1979, p. 5). Por conseguinte, assume-se a intertextualidade como um mecanismo da leitura literária, suscetível de produzir significância. Aliás, ainda nesta linha de pensamento, esclarece Linda Hutcheon que "é apenas como parte de discursos anteriores que qualquer texto obtém sentido e importância" (HUTCHEON, 1991, p. 166).

Posteriormente, partindo do pressuposto da ambiguidade do termo "intertextualidade", devido ao seu amplo uso no discurso literário, Tiphaine Samoyault reelabora este conceito, baseando-se na noção de memória, que implica uma dinâmica, um "jogo" constante entre o antigo e o novo. Desse modo, se "cada texto constrói a sua própria originalidade, inscreve-se, ao mesmo tempo, numa genealogia que ele pode mais ou menos explicitar" (SAMOYAULT, 2008, p. 9). Nesse sentido, a presença de um autor, de um texto, em outro, pode acontecer de forma aleatória ou consentida, como homenagem explícita ou ainda submissão a um modelo, subversão do cânone ou inspiração voluntária, assumindo as mais diversas formas (citação, alusão, referência, pastiche, paródia, colagens, plágio etc.). Com efeito, essa presença dos intertextos, das "vozes" dos outros autores assume-se como uma porta para a instauração da alteridade, já que:

$\mathrm{Na}$ intertextualidade, a alteridade é necessariamente atestada pela presença de um intertexto: ou a fonte é explicitamente mencionada no texto que o incorpora ou o seu produtor está presente, em situações de comunicação oral, ou ainda, trata-se de provérbios, frases feitas, expressões estereotipadas ou formulaicas, de autoria anônima, mas que fazem parte de um repertório compartilhado por uma comunidade de fala (KOCH, 1997, p. 57).

Verificamos, por conseguinte, que muitos dos intertextos que transparecem na obra de Ana Margarida de Carvalho fazem parte de um repertório 
compartilhado pela comunidade, como é o caso de expressões retiradas da lírica trovadoresca ou de peças de Gil Vicente, em uma nítida homenagem à literatura e à tradição cultural portuguesa ou, ainda, a utilização de dois versos da canção de embalar do cantor Zeca Afonso, para enfatizar a profunda ligação de Teresa ao filho, prenunciando, simultaneamente, o final trágico da criança: "O meu menino é d'oiro, d'oiro é o meu menino, Hei-d’intregá-lo ós anjos, p’ra lembrar qué pequenino" (CARVALHO, 2018, p. 19).

Contudo, visto que o nosso objetivo não é analisar exaustivamente a densa presença da intertextualidade nos romances, mas, sim, equacionar o modo como ela se assume como forma de instaurar a alteridade, centraremos nossa atenção, sobretudo, na análise de alguns paratextos ${ }^{2}$ mais especificamente, do curto prefácio de The Ship of Fools e das epígrafes. Nesse contexto, é pertinente mencionar que, segundo Compagnon (1996, p. 120), a epígrafe "é a quintessência da citação, a que está gravada na pedra para a eternidade". Ela tem as funções de apresentar, inferir, resumir. É lançada uma proposição que é mantida como premissa e funciona como plataforma a partir da qual o texto se constrói. É nesta "plataforma" que encontramos o título Não se Pode Morar nos Olhos de um Gato, colhido do "Poema de Desamor" de Alexandre O’Neil: "Queixa-te coxa-te desnalaga-te desalma-te / Não se pode morar nos olhos de um gato" (CARVALHO, 2018, p. 7). Esses são dois dos versos de um poema de teor surrealista em que transparece revolta e agressividade, apresentados como epígrafe. Tal como refere Helena Vasconcelos (2016, p. 2),

é compreensível que seja O’Neil a funcionar como pedra de toque desta narrativa em que o virtuosismo da linguagem, o ritmo das palavras, a agilidade do discurso e as imagens surrealizantes se sucedem em catadupa, numa torrente imparável e avassaladora.

Com efeito, esses dois versos de O'Neil surgem juntamente com mais duas outras epígrafes, uma extraída da letra de uma canção do cantor de intervenção José Mário Branco e outra da autoria de um menino de quatro anos chamado João Manso Pinheiro.

Nessa sequência, os versos extraídos do "Canto dos Torna-Viagem" de José Mário Branco anunciam a questão da alteridade e sua relação com a identidade, remetendo para o modo como cada indivíduo é visto e percebido pelos outros, muitas vezes, de forma superficial, de acordo com a sua aparência e circunstância:

Tentemos então ver a coisa ao contrário

Do ponto de vista de quem não chegou

Pois se eu fosse um preto chamado Zé Mário

Eu não era quem eu sou (CARVALHO, 2018, p. 7).

Esse é um convite a uma mudança de perspetiva na reflexão sobre o modo como nos percecionamos a nós próprios, aos outros e às múltiplas óticas que 
podem ser adotadas para uma apreensão mais completa das dimensões do "outro", encontrando-se subjacentes às questões de racismo e de exclusão social que surgirão no romance.

Por fim, a epígrafe de João Manso-Pinheiro: "É muito raro, mas às vezes acontece" (CARVALHO, 2018, p. 7), de aparente simplicidade, espelha uma sabedoria mais profunda, preparando-nos para a instauração do improvável e do inusitado que emergirão no romance. Paralelamente, nota-se uma valorização de elementos essenciais, geralmente escamoteados em detrimento de uma apreensão superficial da realidade.

Além disso, no primeiro capítulo, o discurso barroco torrencial da santa integra uma evocação de pragas de cariz popular, rogadas pelas personagens vicentinas, nomeadamente, pelo "Parvo" de O Auto da Barca do Inferno: "que não vos posso acudir, piratas, bucaneiros, flibusteiros, negreiros, remelentos, entronchados, que não há barca que aguente males tão torpes no mundo. Ide-vos e me desamparades, cornudos, fideputas, samicas de cagamerdeiros, má rabugem que vos dê...”. (CARVALHO, 2018, p.10). Essa mobilização de uma obra com um forte teor crítico e satírico, sobejamente conhecida pela comunidade de leitores portugueses, visto ser de estudo obrigatório nas escolas, prepara a entrada num universo onde o mal será a tônica dominante, sendo criticada a desumanidade. Nesse caso, a inscrição da "Barca do Inferno" e do "parvo", remetem-nos quase inconscientemente para The Ship of Fools, obra também marcada, desde o título, pela intertextualidade. Aliás, no curto prefácio, Porter afirma que o título do livro é a tradução de Das Narrenschiff ${ }^{3}$, alegoria moral de Sebastian Brant (1458?1521), publicada, primeiramente em latim, como Stultifera Navis 4 , em 1494. Tal como menciona a autora na sua breve nota:

Li-a em Basileia no Verão de 1932, quando ainda tinha nítidas na memória as impressões da minha primeira viagem à Europa. Quando comecei a pensar no meu romance, apropriei-me dessa imagem simples e quase universal da nau do mundo na sua viagem para a Eternidade. Ela não tem nada de novo, pois já era bastante antiga, usada, familiar e muito querida quando Brant a usou, e serve exatamente o meu propósito. Eu própria sou uma passageira dessa nau (PORTER, 1984, minha traduçãos).

Desse modo, a autora assume ter se apropriado da imagem já tão antiga e universal do navio do mundo, no seu percurso rumo à Eternidade, remetendo, paralelamente para a sua experiência pessoal e para a viagem realizada, em 1931, entre o México e a Europa, em uma embarcação que teria semelhanças com o "Vera". Nessa linha de pensamento, podemos considerar que nos deparamos com um processo de compreensão que evolui do concreto para o abstrato, extraindo elementos de uma experiência real que serão, depois, transpostos e figurados no domínio ficcional.

Diferentemente do que sucede no romance de Ana Margarida de Carvalho, no qual como já referimos, as epígrafes se encontram concentradas em uma mesma página, no início da obra, em The Ship of Fools, as três epígrafes abrem 
cada uma das partes e iluminam o seu conteúdo. A primeira é um verso do poeta francês Baudelaire: "Quand partons-nous vers le bonheur?"6 (PORTER, 1984, p. 2) e espelha as esperanças que habitam os passageiros ao iniciarem a viagem. A segunda, que abre a parte intitulada "High Sea" é retirada de uma canção de Brahms, "Kein Haus, keine Heimat ${ }^{8 ”}$ (PORTER, 1984, p. 69) expressa a solidão e a infelicidade de um indivíduo à deriva, desenraizado. Por último, a terceira parte "The Harbors" abre com uma frase de São Paulo: "For here have we no continuing city...” (PORTER, 1984, p. 361). Deparamo-nos, assim, com uma trajetória iniciada, sob a égide das ilusões das personagens, esperançosas de que a travessia as conduzirá a uma situação e espaço melhores, consubstanciados, para muitas, num regresso a uma pátria imaginada. A seguir, verifica-se uma imersão na alienação, na loucura, na dor e nas desilusões que desaguam na incerteza patente na frase de São Paulo. Tal como refere Unrue, salientando a intertextualidade que impregna esse romance:

A Nau dos Loucos, uma variação de A Odisseia e uma sátira clássica no espírito de Erasmus, Swift e Lawrence Sterne, está repleta de sagacidade dilacerante e pronunciamentos sobre a loucura humana. Das muitas ironias, a mais forte está na própria viagem: todos os passageiros pensam que estão viajando para um lugar melhor do que aquele que deixaram, e um número significativo acredita que estão regressando a casa, aquele refúgio de conforto e amor. Para onde todos eles vão, é claro, é para o eminente colapso da civilização moderna (UNRUE, 2005, p. 256, minha tradução $\left.{ }^{9}\right)$.

Em suma, o ponto de partida dos dois romances, de onde emergem as vozes de diversos autores, de diferentes épocas, provenientes não apenas do mundo da literatura, mas também, por exemplo, da música, é a simbólica imagem do navio, em que embarcam personagens representativas de diversas nacionalidades e classes sociais. Nesse contexto, importa ainda referir o fato de o navio se assumir, segundo Foucault, como um espaço heterotópico por excelência, ou seja, um espaço de alteridade, visto que "o barco é um pedaço flutuante de espaço, um lugar sem lugar, que vive por si mesmo, que é fechado sobre si e é entregue, ao mesmo tempo, ao infinito do mar" (FOUCAULT, 2013, p. 121) ${ }^{10}$. Nesse sentido, navegando rumo a outras realidades, permitindo o intercâmbio de mercadorias e ideias, o barco desenhou-se, ao longo do tempo, como força motriz de desenvolvimento econômico, espaço de aventura, de sonho, de múltiplas significações. Será precisamente esse espaço heterotópico do navio, o palco da inter-relação entre as personagens que funcionará como eixo fundamental nos dois romances, conferindo uma dimensão poliédrica e mais profunda à alteridade.

\section{Os olhares sobre o outro: alteridade e preconceito}

A alteridade é a primeira dimensão que se destaca, desde o primeiro olhar lançado entre as personagens dos dois romances. Nesse contexto, é pertinente 
relembrar que o conceito de alteridade se define a partir do "outro", ou seja, do termo complementar de referência, apontando implicitamente para algo que não se adequa dentro do horizonte de subjetividade, experiência ou expectativa, não sendo considerado como "normal". Em outras palavras, encerra em si as ideias de diferença e de estranhamento. Tal como discute Paul Voestermans (1991, p. 219, minha tradução ${ }^{11}$ " A alteridade pode ser amplamente definida como um discurso sobre a alteridade das pessoas, determinadas pessoas fora de seu conhecimento doméstico". Assim, em The Ship of Fools, desde o momento do embarque, evidencia-se a desconfiança nos olhares das personagens e delineiamse os estereótipos e preconceitos agudizados, ao longo da viagem, cuja primeira escala será em Cuba.

Como discutido anteriormente, todas as personagens com maior relevo viajam na primeira classe, sendo notório o misto de repugnância e fascínio com que observam o "rebanho humano" da terceira classe, através de uma grade que permite ver as profundezas do navio, povoadas por oitocentas e setenta e seis pessoas. Essa aversão ao "outro" é expressada pela alemã Frau Rittersdorf, logo na fase inicial da viagem: “Há um grande perigo de doenças infeciosas entre essas criaturas', disse ela a Herr Baumgartner ao seu lado. 'Eu pergunto-me não devemos reclamar com o capitão? Afinal, não viajamos em um barco de gado"' (PORTER, 1984, p. 60, minha tradução ${ }^{12}$ ). Transparece aqui um profundo preconceito, pois este "outro" é considerado inferior devido à pobreza e rebaixado ao nível dos animais. Mais adiante ainda, preconceito e rejeição emergem de forma mais notória através do olhar e da reflexão de Freytag, motivada pela contemplação do fundo do navio e o amontoado de corpos. Tendo pertencido sempre a um meio social privilegiado, Freytag evidencia uma aversão moral à pobreza: "Um desprezo e desconfiança instintivos relativamente aos pobres que enxameavam, desabrochando como vermes na sujeira, sujando o ar ao seu redor" (PORTER, 1984, p. 63, minha tradução ${ }^{13}$ ).

$\mathrm{Na}$ verdade, esse mundo onde se movem as personagens mais relevantes é marcado pelo confinamento, não apenas espacial, mas das próprias mentes fechadas, povoadas por preconceitos individuais ou de grupo, racismo e discriminação mútua. Nesse âmbito, verificamos que Frau Rittersdorf é satirizada, não apenas por preconceito relativamente à classe social mais baixa, mas também pelo seu racismo e posição anti-americanista, pois tal como refere: "A miscigenação gradual daquele lamentável país pela mistura do rebotalho da Europa emigrado com os negros resultou em uma indescritível mediocridade de caraterísticas e de espírito" (PORTER, 1984, p. 83, minha tradução ${ }^{14}$ ). No fundo, esta posição é também partilhada pelo comandante do navio, para quem os americanos são considerados como gangsters bárbaros, sobretudo devido à miscigenação, pois como afirma Rittersdorf em outra passagem: "Eu não confio nos americanos - todos eles têm sangue índio, negro ou judeu, mestiços e selvagens. Eles sequestram criancinhas por dinheiro e depois as matam" (PORTER, 1984, p. 251, minha tradução ${ }^{15}$ ). Neste caso, verificamos também a emergência do anti-semitismo, pois o "sangue judeu" é mais outro foco de "contaminação" do povo americano. 
Por sua vez, o texano William Denny também é satirizado pelo olhar negativo lançado aos passageiros de outras nacionalidades, devido à sua intolerância e preconceitos. Revela o orgulho de ser filho de um proeminente cidadão de Brownsville, evidenciando uma atitude preconceituosa e etnocêntrica, ao evocar sua cidade de origem como um espaço "Onde um homem sabia quem era quem e com quem se metia, e onde negros, suecos loucos, judeus, engraxadores, mexicanos, porto-riquenhos e yankees malditos conheciam o seu lugar e não saiam dele" (PORTER, 1984, p. 334, minha tradução ${ }^{16}$ ). Preconiza, desse modo, uma apologia da segregação a todos os níveis. Além disso, devido ao seu comportamento misógino e disfuncional, é caracterizado por Herr Glocken, um dos seus companheiros de camarote, como um monstro, "Certamente não é bem humano" (PORTER, 1984, p. 469, minha tradução ${ }^{17}$ ).

Ao longo da obra, através do modo como os diversos passageiros se interrelacionam, descobriremos seus pontos fracos, incoerências e defeitos. Eles são observados de fora, no âmago do microcosmos do navio, numa multiplicidade de pontos de vista, como se o narrador onisciente possuísse uma câmera que fosse filmando as personagens em diversos planos.

Por seu turno, em Não se Pode Morar nos Olhos de um Gato são evidentes as atrocidades cometidas contra escravos e marinheiros, assim como as desigualdades sociais e o estranhamento face ao "outro". Nesse contexto, uma das reações comuns, no exercício da alteridade, é a tendência para reduzirmos a diferença à familiaridade, numa tentativa de visualizarmos o "outro" como um prolongamento de nós mesmos, absorvendo-o, desrespeitando-lhe a unicidade e a diferença. De modo semelhante ao que sucede em The Ship of Fools, também neste romance, as relações entre as diversas personagens são pautadas, desde o início, pela hostilidade consubstanciada numa tentativa de aniquilamento do "outro". Tal fato espelha-se, por exemplo, no olhar hostil lançado aos outros pelo padre Marcolino, que como representante da igreja, deveria revelar uma postura mais tolerante. Excetuam-se dessa visão negativa, Teresa e a filha, pois esta continua a ser "a sua senhora" num prolongamento das relações sociais estabelecidas antes do embarque no navio. Nessa esteira, por exemplo, o jovem solitário, Nunzio, é visto pelo padre como "falhado, infecundo [...] sarnento, indecente, com aquela crina obstinada que ele nem tenta acamar [...] (CARVALHO, 2018, p. 94-95). É, portanto, considerado "ridículo e grotesco" (CARVALHO, 2018, p. 95), devido à sua postura e apresentação pessoal que destoa dos paradigmas de Marcolino. Também o olhar lançado ao capataz é profundamente negativo. Para o padre, ele é o "homenzarrão peludo e bruto" que "pisava o risco, sem subtilezas, sem subterfúgios, atentava ao pudor e ao respeito, como se aquela praia fosse o seu reino, e eles os vassalos, que the deviam obediência e cabeça baixa" (CARVALHO, 2018, p. 103). Notamos que o capataz transpõe para aquela remota praia o comportamento tirânico que exercia sobre os escravos, mostrando um completo desrespeito pelo "outro", como se eles fossem desprovidos de direitos. De um modo geral, é caracterizado pelos outros como o "boçal chicoteador de escravos". 
O estranhamento atinge, no entanto, o seu ponto culminante na relação que as diversas personagens estabelecem com o escravo. Ele é o último a aparecer na praia, montado num cavalo moribundo. É violentamente chicoteado pelo capataz, como se o seu estatuto de escravo - apesar de a ação se desenrolar após a abolição da escravatura, o que denuncia a hipocrisia das leis que não eram cumpridas - não o autorizasse a sobreviver nem a partilhar o mesmo espaço dos outros. Evidencia-se o fato de ser concedido ao escravo (que só mais tarde saberemos chamar-se Julien) um tratamento inferior ao que é dado aos animais: “[...] o criado a levar ao escravo uns restos indistintos antes que aquela gente devorasse tudo, e o escravo de mãos atadas, com a cabeça entre as pernas, a tentar com os beiços separar as espinhas do peixe e a cuspir o que os dentes não conseguiam trinchar" (CARVALHO, 2018, p. 110). Assim, ele se alimenta dos restos e isso apenas devido à solidariedade do criado, já que são as duas personagens situadas na escala inferior, do ponto de vista social. Como contraponto a essa discriminação, assistimos a uma valorização do escravo, através da focalização interna, reveladora da sua perplexidade e desconfiança perante os outros:

Do homem do chicote que lhe atravessara a pele quase até ao músculo sabia o que esperar, desde que se contentasse só com o couro, pior eram os outros que lhe queriam comer, estava certo disso, as entranhas. Aquelas mulheres horríficas deixavam um lastro na areia como lesmas, de vestidos e cabelos pingados, o sinistro ser que se vestia de preto até o pescoço, branco por dentro, e falava com o ar, mandava no vento com os dois dedos e tocava-se a si próprio, quatro vezes, da boca para o peito, de um lado e do outro. Era o sinal da fome que ele tantas vezes vira repetir [...]. Depois normalmente soltavam o som de um bezerro. Ámennnnnnn. Era o alívio, sinal de que ainda tinham animais para comer antes de passarem à carne dos cativos (CARVALHO, 2018, p. 106).

Não podemos deixar de notar o sarcasmo que impregna o pensamento aparentemente ingênuo do escravo, receando ser comido pelos brancos, o que instaura uma dimensão poliédrica da alteridade, ao enfatizar esta postura do "outro". Tal fato adquire sentido, visto que os escravos são tratados de pior forma que os animais destinados a abate e consumo. $\mathrm{O}$ fato de a palavra conclusiva da oração, o "Amén" ser comparada ao som de um bezerro adquire verosimilhança, na medida em que esse olhar é lançado à luz das vivências e do universo habitado pela personagem. Afastando-se do etnocentrismo, o narrador concedenos o acesso ao olhar distinto do "outro", do subalterno, inferiorizado pelos preconceitos e estereótipos veiculados do ponto de vista social. Nesse contexto, tal como refere Pieterse (1991, p. 201), a alteridade é o limite da normalidade, visto que as suas imagens exercem uma função disciplinar, como espelhos da diferença, marcadores, sinais de aviso. Nesse caso, encontramos, através da voz do escravo, uma subversão dos significados dos padrões a que supostamente se atribuiriam os adjetivos "selvagem" e "civilizado". Desse modo, os brancos, que seriam aparentemente os "civilizados", foram considerados capazes das piores selvagerias e do tratamento mais desumano. 
Em suma, podemos verificar que o olhar de desconfiança, por vezes, mesmo de aversão ao "outro" emerge nos dois romances, embora com contornos distintos. Contudo, em The Ship of Fools notamos que o olhar preconceituoso lançado aos membros de determinadas nacionalidades, se enraíza num estereótipo desses povos. De modo um pouco diferente, na obra de Ana Margarida de Carvalho, embora as personagens também sejam representativas de classes sociais distintas (não de nacionalidades especificas), há uma dimensão pessoal e subjetiva que é valorizada. Em comum, transparece-se o fato de um maior distanciamento e mesmo "aversão" ser dirigido aos mais desfavorecidos, o que pode funcionar, em ambos os casos, como uma advertência perante o problema das desigualdades sociais tão importante nos anos sessenta do século XX, como em pleno século XXI.

\section{A mesa do capitão: da desigualdade à subversão}

Em ambos os romances, "a mesa do capitão" é delineada como um símbolo do poder e dos privilégios acessíveis apenas a uma elite minoritária. Por isso, ela se assume também como um meio de sublinhar as desigualdades e injustiças sociais, assim como a discriminação.

Em The Ship of Fools, apenas uma pequena elite, formada por alemães, encontra-se autorizada a partilhar a mesa do capitão, que encerra em si as caraterísticas de um típico ditador. Aliás, ele preconiza um sistema autoritário, de privilégios, baseado numa ordem social hierarquizada à semelhança de uma ordem divina, sendo apresentado como "Um deus menor: um deus que se tornou um tanto petulante e mais do que mesquinho em seus esforços para manter a autoridade" (PORTER, 1984, p. 174, minha tradução ${ }^{18}$ ). Curiosamente, esse "deus menor" que pode ser entendido como um genuíno representante de Hitler, alude, através do seu nome, ao General Fritz Thiele, que serviu no exército alemão, durante a Primeira e a Segunda Guerras Mundiais acabando por integrar a Resistência Alemã. Tal fato conduziu à sua execução em 1944, após uma tentativa fracassada de assassinato de Hitler (UNRUE, 2015, p. 217). Por conseguinte, a escolha do nome acaba por ser irônica, na medida em que funciona como uma subversão dos ideais do nazismo, através da evocação de um de seus mártires, instaurando uma nova possibilidade à qual este grupo de alemães é completamente alheio.

No primeiro encontro à mesa, um dos vícios caricaturados é o da gula: "saborearam com sôfrego apetite a esplêndida e substanciosa comida alemã" (PORTER, 1984, p. 40, minha tradução ${ }^{19}$ ). Também, neste caso, a intertextualidade marca presença, pois tal como nota Daphinoff, este é um dos pecados representados, tanto no poema de Brant, quanto na pintura de Bosch (2015, p. 33). Nesse caso, esse pecado caracteriza as personagens dominantes, todas de nacionalidade alemã.

No convívio a essa mesa também emergem o nacionalismo, o racismo e o nazismo de outras personagens. Um dos exemplos é o professor Hutten que foi diretor de uma escola alemã na Cidade do México e que julga fazer parte de 
um movimento universal com o intuito de melhorar a humanidade ao aniquilar, através da repressão, hábitos estrangeiros considerados perniciosos, notados entre os seus estudantes. Do mesmo modo, Hutten será um dos apoiadores da expulsão de Freytag daquela mesa. Freytag, apesar de ser um protótipo exemplar da raça ariana, é casado com uma judia, o que determina a sua exclusão. A informação de que um dos convivas da mesa não teria o direito de ali estar é transmitida por Frau Lizzie e Herr Rieber. Nessa ocasião, Hutten reafirma a sua crença na superioridade da raça alemã, ao enfatizar as vantagens daquela decisão com o intuito de: "para nos lembrar claramente de nossos princípios e para ver se estamos ou não em harmonia com o grande padrão da nossa tradição" (PORTER, 1984, p. 245, minha tradução ${ }^{20}$ ). Por conseguinte, Freytag é condenado à ostracização e senta-se na companhia de Lowenthal, o judeu também excluído, esboçando-se um quadro do anti-semitismo criticado na obra.

Tal como nota Bloemendaal, a docilidade dos alemães à mesa do comandante revela a submissão, a obediência ao regime nazi (2005, p. 181). Aliás, os alemães revelam um comportamento coeso, espelhando os pensamentos e atitudes do seu comandante: "O anel estava fechado solidamente contra todos os indesejáveis, tanto aliados quanto inimigos. [...] Todos os rostos estavam relaxados [...] eles eram, afinal, eles próprios e mais ninguém: os poderosos, os privilegiados, as pessoas certas" (PORTER, 1984, p. 247, minha tradução $0^{21}$ ).

Esse privilégio vai ser parodiado e subvertido pela zarzuela espanhola, um dos grupos mais discriminados na primeira classe, juntamente com os estudantes cubanos. Com efeito, de forma sarcástica, os membros da zarzuela ocuparão, efemeramente, esse lugar de honra, através de um processo conduzido ilicitamente. Desse modo, os elementos da trupe organizam rifas que consistem em bilhetes para organizar uma festa de homenagem ao comandante. Durante a escala feita em Tenerife, eles saqueiam as mais diversas lojas de artesanato de onde trazem os prêmios para o referido sorteio. Reúnem, assim, as condições para organizar o banquete que lhes permitirá ocupar esse lugar de privilégio. Perante tal acontecimento, o capitão deixa transparecer a indignação e desagrado, aliados à impotência para controlar a situação e à incompreensão relativamente ao modo como teriam eles conseguido chantagear tanta gente e obtido lugares à sua mesa, onde ele considerava que não estavam autorizados a se sentarem. Em contrapartida, os membros da zarzuela manifestam euforia pela posição conquistada, que funciona como contraponto à discriminação de que foram vítimas:

Os sorrisos dissiparam-se, os seus olhos tornaram-se duros, cintilantes, selvagens, triunfantes enquanto olhavam para os outros passageiros, alguns dos quais ainda fingiam ignorá-los. Deixá-los! Nem por um momento eles esqueciam o significado da sua vitória (PORTER, 1984, p. 439, minha tradução ${ }^{22}$ ).

Nesse caso, emerge nitidamente uma ascensão do "outro" discriminado, ignorado, visto com desconfiança, quer devido à sua origem, quer aos distintos modos de agir e de comportar. Desenha-se, assim, ainda que brevemente, o 
triunfo do antagonista, dos elementos instauradores da diferença. Outro elemento relevante é o fato de essa vitória ser obtida desonestamente, o que espelha o modo como, muitas vezes, se acedem aos privilégios na sociedade do mundo real. Além disso, segundo Knape (2013, p. 164), não apenas os membros da zarzuela, mas também o grupo de estudantes cubanos, representam os antagonistas, ou seja, o modelo oposto de desvio e caos.

Desse modo, a ação de The Ship of Fools vai progredindo, desde o antisemitismo e as mais diversas manifestações nacionalistas e discriminatórias, evidenciadas à mesa do comandante, aos diálogos e atitudes das diversas personagens, rumo a uma alienação que culmina neste banquete em honra do capitão, no qual os antagonistas assumem o poder e se instaura o caos. A alienação atinge o seu ponto culminante nas ações praticadas pelas diversas personagens em estado de embriaguez, durante e depois do banquete. Assim, Jenny desaparece com Freytag, traindo o noivo, David; Denny procura vingar-se da rejeição de Pastora, sendo agredido por Mrs. Treadwell, a quem inadvertidamente importuna, confundindo-a com a bailarina espanhola; o sueco Hansen agride Herr Rieber. Por outras palavras, o estado de alienação gerado pelo consumo de álcool provoca a emergência dos instintos mais animalescos, tornando mais acutilantes os conflitos entre as personagens.

Por sua vez, no navio negreiro de Não se Pode Morar nos Olhos de um Gato, encontramos uma estratificação semelhante à do "Vera" de The Ship of Fools, sendo, neste caso, o porão ocupado pela massa humana e maltratada dos escravos, e a parte de cima pelas outras personagens.

Do mesmo modo, também "a mesa do capitão" marca presença, embora assuma alguns contornos específicos. A alusão a essa "mesa" surge no primeiro capítulo, antes do naufrágio, visto que, depois, o espaço de ação das personagens será a praia deserta. Nesse caso, é descrito um cenário de fome generalizada que afeta os marinheiros e os escravos: "não há comida, encolhe-se a ração, os marinheiros mastigam o ar, procuram peixe" (CARVALHO, 2018, p. 12). Em contrapartida, os três cavalos que o capitão inglês transporta, a sua carga mais preciosa, suscetível de lhe render muito dinheiro, encontram-se bem tratados e alimentados. Impelidos pela fome alguns marinheiros abatem e comem um cavalo sem autorização do capitão. Ao aperceber-se, ele tortura-os recusandolhes qualquer alimento. Simultaneamente, o capitão e Teresa, a esposa do dono do barco, os filhos e os outros passageiros deliciam-se com perna de capão, nozes e outras iguarias. Os marinheiros são obrigados a assistir, enquanto "o capitão faz questão de que todos sejam servidos com abundância”. Para além de uma configuração das desigualdades e das injustiças sociais, neste banquete, que funciona como uma forma de tortura, não se evidencia qualquer empatia ou afinidade entre os comensais, pois "o capitão tenta encetar conversas, mas elas mal se levantam, morrem numa espuma inútil, como uma onda ridícula" (CARVALHO, 2018, p. 25). Essa comparação enfatiza a falta de sentido e o absurdo daquela situação, tornando-se o ato de tortura mais requintado quando o capitão se levanta, aproxima-se dos marinheiros, enquanto "exige a denúncia 
dos responsáveis, leva-lhe um pedaço de carne cozinhada junto à cara de cada um, despeja-lhes o vinho no chão" (CARVALHO, 2018, p. 26). Evidenciam-se alguns traços que aproximam este capitão inglês sem nome do alemão Thiele, como o autoritarismo, a crueldade, embora a violência e o caráter desumano sejam aqui mais acentuados. O exemplo mais notório da sua desumanidade revela-se quando manda afogar um jovem, por ter ousado rir diante dele. Será após essa trágica morte, que acontece o naufrágio.

Posteriormente, refugiados na praia deserta, os sobreviventes deparam-se com um novo "capitão", o capataz, cuja "mesa" também será inicialmente restrita, visto que ele instaura um controle através da posse dos alimentos e da água potável, pois o seu conhecimento das táticas de sobrevivência vai acentuar essa supremacia. Isso apesar de, mais tarde, a "liderança" ser partilhada com Teresa e, no final, emergir, devido à sua força e astúcia, o mais improvável dos líderes, o escravo. Esse inesperado desenvolvimento deixa transparecer o desejo de conceder voz ao "subalterno" e de valorizar os que são vítimas da mais injusta discriminação e preconceito.

Na verdade, diferentemente do que sucede em The Ship of Fools, em Não se Pode Morar nos Olhos de um Gato, o processo de alienação e desumanização que afeta as personagens, aproxima-as e a "mesa do capitão" acaba, numa fase final, por se converter no espaço onde cada um ocupa o seu lugar. Os seus preconceitos atenuam-se, à medida que as roupas se rasgam e degradam. A inicial aversão ao "outro", devido ao instinto de sobrevivência. é substituída pela necessidade de cuidar de si e do "outro", configurando-se aquele grupo como uma improvável comunidade, unida pelo objetivo de sobreviver em território inóspito:

A comunidade também partilhava momentos alegres, quando encurralados pelo mar tinham de esperar que a maré vazasse, a sustentar o tédio, o ócio, o aperto em que todos se encontravam, impossível não se tocarem, não sentirem a pele e o hálito uns dos outros (CARVALHO, 2018, p. 206).

Não obstante, tal como sucede na obra de Porter, também aqui, não surgem personagens que funcionem como modelos ou heróis. Todas elas encarnam os mais diversos pecados ou crimes cometidos no passado, que se vão desvelando progressivamente e que motivaram, de forma direta ou indireta, o embarque naquele navio. Em breves linhas, Marcolino abandonou os pais na pobreza; Maria Teresa, envolvida no comércio de escravos, embarcou com a filha para encobrir a misteriosa gravidez indesejada da jovem; por sua vez, Emina oculta o fato de a origem do seu estado ter sido o incesto cometido com o pai; Maria Clara (no início disfarçada de criado José) tentou escapar à miséria através da prostituição, primeiro em Coimbra e depois em Angola onde adoeceu gravemente e foi salva pelo capataz; Julien, cujo nome colocado por uma patroa que o protegeu, em homenagem a Julien Sorel, o protagonista de Le Rouge et le Noir de Stendhal, maltratou outros escravos, e assassinou o seu melhor amigo, motivado por ciúmes. Por sua vez, Nunzio traiu o pai, tendo vendido, sem o seu conhecimento, a casa por ele habitada e condenou à morte a fiel cadela Anástasia. 
Assim, em ambos os romances, os abismos interiores de cada individuo são desvelados através do exercício da alteridade. Não obstante, se em The Ship of Fools, emerge o confronto do sujeito perante a opressão do coletivo, em Não se Pode Morar nos Olhos de um Gato, essa tensão e hostilidade relativamente ao "outro" acaba por ser ultrapassada por meio da emergência de um sentido de "comunidade", única possibilidade de sobrevivência num cenário adverso.

\section{Considerações finais}

A título de conclusão, podemos referir que Não se Pode Morar nos Olhos de um Gato evidencia a presença de alguns elementos colhidos de The Ship of Fools, filtrados e originalmente recriados por Ana Margarida de Carvalho, como é o caso da imagem do navio, espeço heterotópico por excelência, onde, como anteriormente referimos, ecoam as vozes de outros autores anteriores a Kaherine Porter.

Assim, partindo da intertextualidade que habita as duas obras e instaura uma relação dialógica, sedimentada depois pelo exercício da alteridade, ambos os romances transpõem para o universo ficcional, elementos fulcrais da condição humana da qual o mal é um componente essencial. Aliás, como já referimos, em nenhum deles existem personagens exemplares, pois todas encarnam diversos defeitos e preconceitos, tendo sido utilizados por Porter, para advertir contra o nazismo, o anti-semitismo e os nacionalismos. Dessa forma, como refere Daphinoff $(2015$, p. 33), The Ship of Fools não propõe qualquer alternativa à loucura ou à destruição, pois a tranquila chegada ao porto alemão será um passo para o fim de uma civilização, do qual ninguém parece estar ciente. Em contrapartida, na obra de Ana Margarida de Carvalho, há uma esperança acesa, uma possibilidade consubstanciada na tentativa de fuga da praia. No final do romance, após a morte acidental do capataz (ironicamente empalado pela santa), Julien, que esboçara com ele o plano de fuga, converte-se no único líder da travessia rumo a uma talvez improvável "terra prometida". Ou seja, se em Porter não se vislumbra a salvação, neste caso, ela talvez possa ainda existir.

De um modo geral, ambos os romances, ao encenarem as contradições da nossa relação com o mundo e com o "outro", provocam o desconforto de explicitar os aspetos negativos da natureza humana, através da exploração de temáticas comuns, como é o caso da opressão, resistência ao poder, injustiça, racismo, e desigualdades sociais. Temas estes cada vez mais relevantes nas sociedades do século XXI, onde, escamoteados no conforto de alguns direitos considerados adquiridos, continuam a germinar a discriminação, o preconceito, a injustiça e, inclusive, a emergência de relações laborais suscetíveis de reinventar novos tipos de escravatura. Em outras palavras, uma sociedade onde o acesso "à mesa do capitão" será cada vez mais estrito, ao contrário do que seria de supor, levando em conta os processos de democratização, implementados ao longo das últimas décadas.

No fundo, é a imperfeição inerente à condição humana (e, por isso, intemporal) que é, nessas obras, desvendada, visto que todos nós poderemos ser os passageiros dos navios, assim como os sobreviventes na praia deserta, em fuga rumo ao desconhecido. 
Notas

1. No original: "any text is the absorption and transformation of another. The notion of intertextuality replaces that of intersubjectivity, and a poetic language is read as at least double" (KRISTEVA, 1980, p. 66).

2. Gerard Genette analisa a paratextualidade, ou seja, a transcendência textual. Nesse estudo, é contemplada a relação geralmente menos explicita e mais distante, entre uma obra literária e o seu paratexto, que engloba: títulos, subtítulos, prefácios, dedicatórias, ilustrações e vários outros tipos de sinais acessórios (GENETTE, 1982, p. 10).

3. A Nau dos Loucos.

4. A Nau dos Loucos.

5. No original: "I read it in Basel in the summer of 1932 when I had still vividly in mind the impressions of my first voyage to Europe. When I began thinking about my novel, I took for my own this simple almost universal image of the ship of this world on its voyage to eternity. It is by no means new -it was very old and durable and dearly familiar when Brant used it; and it suits my purpose exactly. I am a passenger on that ship" (PORTER, 1984).

6. Minha tradução: "Quando partiremos para a felicidade?”.

7. Minha tradução: “Alto-mar”.

8. Minha tradução: "Sem lar nem pátria".

9. No original: "Ship of Fools, a variation on The Odyssey and a classic satire in the spirit of Erasmus, Swift, and Lawrence Sterne, is full of lacerating wit and pronouncements on human folly. Of the many ironies, the strongest lies in the voyage itself: all the passengers think they are journeying to a better place than the one they left, and a significant number believe they are going home, that haven comfort and love. What they all are going to, of course, is the near-collapse of modern civilization" (UNRUE, 2005, p. 256).

10. A conferência intitulada "De espaços Outros" foi proferida por Michel Foucault no Cercle d'Études Architecturales em 14 de março de 1967, e publicada originalmente em Architecture, Mouvement, Continuité, n.5, outubro 1984, p.469. A versão usada neste artigo é uma tradução de de Ana Cristina Arantes Nasser, republicada na revista Estudos Avançados, no dossier “O espaço na vida social” (2013)

11. No original: "Alterity can broadly be defined as discourse on the otherness of people, particular people outside one's domestic ken” (VOESTERMANS, 1991, p. 219).

12. No original: "There is a great danger of infectious disease among such creatures she said to Herr Baumgartner at her elbow. I am wondering-should we not complain to the Captain? After all, we did not engage to travel on a cattle boat" (PORTER, 1984, p. 60).

13. No original: "an instinctive contempt and distrust of the swarming poor spawned like maggots in filth, befouling the air around them" (PORTER, 1984, p. 63).

14. No original: "The gradual mongrealization of that dismaying country by the mingling of the steerage sweepings of Europe and the blacks had resulted only in a mediocrity of feature and mind impossible to describe" (PORTER, 1984, p. 83).

15. No original: "I do dont trust Americans-they all have Indian, or Negro, or Jewish blood- mongrels and savages. They kidnap little children for Money, and then murder them" (PORTER, 1984, p. 251). 
16. No original "where a man knew who was who and what was was that, and niggers, crazy Swedes, Jews, greasers, boné-headed micks, polacks, wops, Guineas and damn Yankees knew their place and stayed in it" (PORTER, 1984, p. 334).

17. No original: "certainly not quite human" (PORTER, 1984, p. 469).

18. No original: "a minor god: a god who had grown somewhat petulant and more than a little mean in his efforts to maintain authority" (PORTER, 1984, p. 174).

19. No original: "They fel upon their splendid full-bodied German food with hot appetites" (PORTER, 1984, p. 40).

20. No original: "to remind us clearly of our principles, and to see whether or not we are in harmony with the great pattern of our tradition..." (PORTER, 1984, p. 245).

21. No original: "The ring was closed solidly against all undesirables, ally as well as enemy. [...] All the faces were relaxed [...] they were, after all, themselves and no one else: the powerful, the privileged, the right people" (PORTER, 1984, p. 247).

22. No original: "Their smiles faded, there eyes were hard, glittering, savagely, triumphant as they glanced around at the other passengers, some of whom were still pretending to ignore them. Let them! Not for a moment did they forget the point of their victory" (PORTER, 1984, p. 439).

\section{Referências}

AUGÉ, M. Non-lieux, Introduction à une anthropologie de la surmodernité. Paris: Seuil, 1992.

BAUMAN, R. A World of Others'Words Cross-Cultural Perspectives on Intertextuality. Oxford: Blackwell Publishing, 2004.

BLOEMENDAAL, J. Constructing identities ethnicity and race in Katherine Anne Porter. 2005. 240 f. Thesis (Ph.D.) - Faculty of Humanities, University of Leiden, Leiden, 2005.

CARDEN, M. P. Women Writers of the Beat Era: Autobiography and Intertextuality. Virginia: University of Virginia Press, 2018.

CARVALHO, A. M. Não se pode morar nos olhos de um gato. 4. ed. Lisboa: Teorema, 2018.

COMPAGNON, A. O trabalho da citação. Tradução de Cleonice P. B. Mourão. Belo Horizonte: UFMG, 1996.

DAPHINOFF, D. After All, What Is Life Itself?: Humanist Contexts of Death and Immortality in Katherine Anne Porter's Ship of Fools. In: AUSTENFELD, T. (Ed.). Katherine Anne Porter's Ship of Fools: New Interpretations and Transatlantic Contexts. Denton: University of North Texas Press, 2015, p. 31-48.

FOUCAULT, M. De espaços outros. Tradução de Ana Cristina Arantes Nasser. Estudos Avançados, São Paulo, v. 27, n. 79, p.113-122, 2013.

FRIEDMAN, S. Weavings: Intertextuality and the (Re)Birth of the Author Influence and Intertextuality. In: CLAYTON, J.; ROTHSTEIN, E. (Eds.). Literary History. Madison: University of Wisconsin Press, 1991, p. 146-180.

GENETTE, G. Palimpsestes. La Littérature au second degré. Paris: Seuil, 1982.

HUTCHEON, L. Poética do Pós-modernismo: História, Teoria, Ficção. Tradução de Ricardo Cruz. Rio de Janeiro: Imago Editora, 1991.

JENNY, L. A estratégia da forma. Intertextualidades, Poétique, Revista de teoria e análise literária. Tradução de Clara Cabré Rocha. Coimbra: Almedina, 1979. p. 5-49. 
KNAPE, J. Modern Rhetoric in Culture, Arts and Media - 13 Essays. Tradução de Alan L. Fortuna. Berlin, Nova York: De Gruyter, 2013.

KOCH, I. V. A construção dos sentidos no texto: intertextualidade e polifonia. In: KOCH, I.V. O texto e a construção dos sentidos. São Paulo: Contexto, 1997. p. 4657.

KRISTEVA, J. Desire in Language: a Semiotic Approach to Literature and Art. ROUDIEZ, L. (Ed.). Tradução de Thomas Gora e Alice Jardine. Nova York: Columbia University Press, 1980.

PACHECO, P. G. Entrevista a Ana Margarida de Carvalho. Scriptorium, Porto Alegre, v. 5, n. 2, 2019. DOI: https://doi.org/10.15448/2526-8848.2019.2.33487. Acesso em: 15 maio 2020.

PIETERSE, J. N. Image and power. In: CORBEY, R.; LEERSSEN, J. (Eds.). Alterity, identity, image selves and others in society and scholarship. Amesterdã, Atlanta: Rodopi, 1991. p. 191-203.

PORTER, K. A. The Ship of Fools. Boston, Nova York, Londres: Little Brown, 1984

SAMOYAULT, T. A Intertextualidade. Tradução de Sandra Nitrini. São Paulo: Hucitec, 2008.

UNRUE, D. H. Katherine Anne Porter: the life of an artist. Jackson: University Press of Mississipi, 2005.

UNRUE, D. H. Katherine Anne Porter's Ship of Fools: Failed Novel, Classic Satire, or Private Joke? In: AUSTENFELD, T. (Ed). Katherine Anne Porter's Ship of Fools: New Interpretations and Transatlantic Contexts. Denton: University of North Texas Press, 2015. p. 213-236.

VASCONCELOS, H. Os Livros do Apocalipse. Ipsilon, Suplemento do Jornal Público, 21 de maio de 2016.

VOESTERMANS, P. Alterity/Identity: A Deficient Image of Culture. In: CORBEY, R.; LEERSSEN, J. (Eds.). Alterity, identity, image selves and others in society and scholarship. Amesterdã, Atlanta: Rodopi, 1991. p. 219-250.

Recebido em: 06/06/2020

Aceito em: 27/10/2020 